OPEN ACCESS

Edited by:

Raúl Navarro,

University of Castilla-La Mancha,

Spain

Reviewed by:

Anne McMaugh,

Macquarie University, Australia

Giuseppe Mannino,

Libera Università Maria SS. Assunta

Italy

*Correspondence: Alan Parry Roberts

a.p.roberts@reading.ac.uk

Specialty section:

This article was submitted to

Educational Psychology,

a section of the journal

Frontiers in Education

Received: 11 August 2020 Accepted: 18 September 2020

Published: 15 October 2020

Citation:

Roberts AP, Monks CP and Tsermentseli S (2020) The Influence of Gender and Resource Holding

Potential on Aggressive and Prosocial

Resource Control Strategy Choice

in Early Childhood.

Front. Educ. 5:593763.

doi: 10.3389/feduc.2020.593763

\section{The Influence of Gender and} Resource Holding Potential on Aggressive and Prosocial Resource Control Strategy Choice in Early Childhood

\author{
Alan Parry Roberts ${ }^{1 *}$, Claire P. Monks ${ }^{2}$ and Stella Tsermentseli ${ }^{3}$ \\ 'School of Psychology and Clinical Language Sciences, University of Reading, Reading, United Kingdom, ${ }^{2}$ School \\ of Human Sciences, Centre for Vulnerable Children, Young People and Families, University of Greenwich, London, \\ United Kingdom, ${ }^{3}$ Department of Primary Education, University of Thessaly, Volos, Greece
}

Through the lens of resource control and resource holding potential theory, an investigation was conducted into the effect of resource opponent characteristics on frequency of aggressive and prosocial resource control strategy selection in 4-5year-old boys and girls. Children ( $N=92 ; 4-5$ years old) were asked how they would respond to 12 hypothetical resource holding potential (RHP) vignettes, in which resource control opponents varied in 'toughness,' 'physical size' and whether or not they were accompanied by friends. Girls gave significantly more prosocial responses to the vignettes than boys, and boys provided significantly more coercive responses compared to girls with some differences with age. Prosocial vignette responses were given significantly more frequently when the opponent was 'not very tough' as opposed to when they were 'very tough.' Findings suggest that both boys and girls utilise some form of discrimination when deciding on how to respond to resource competition scenarios and that there are some age and gender differences in their reported response strategies. Findings are discussed in terms of resource control and RHP theory. Future study should investigate whether such differences translate into real-world observed resource control behaviour.

Keywords: resource control, aggression, prosocial behaviour, early childhood, gender differences, social dominance, resource holding potential

\section{INTRODUCTION}

Resource control is the acquisition and maintenance of control over a material or social resource and is a fundamental factor in the creation of social hierarchies (Hawley, 1999). Hierarchical social structures and associated social behavioural strategies emerge early in human social development, which has led to researchers proposing their importance as evolutionary selective agents (Bernstein, 1981; Hawley, 1999). As children enter and progress through preschool and the early years of the education system, social pressures lead to the development of prosocial behaviours such as 
cooperation, reciprocity and sharing (Trivers, 1971; Charlesworth, 1996; Hawley, 1999; Roseth et al., 2011) which in turn become key behaviours in attaining resource control, particularly when used in combination with aggression (Hawley, 2002; Pellegrini et al., 2007b, 2011; Roseth et al., 2011; Wettstein et al., 2013).

Resource control theory (Hawley, 1999) suggests that both prosocial and coercive behaviours are viable strategic approaches to attaining and maintaining control of resources. The theory defines social dominance as 'the exercise of chief authority or rule - or occupying a commanding position' (Hawley, 2014, p. 327), and contends that an individual's social dominance is established by successful implementation of resource control strategies, that are part of a two-dimensional prosocial/coercive resource-directed behavioural spectrum. The theory can be applied to human behaviours across the lifespan - not just in young children - with research even linking the impact of insecure attachment to coercive resource control strategies in middle childhood (Chen and Chang, 2012) and adulthood (Hawley et al., 2009; Chen, 2017). However, to date there is limited research within the framework of resource control theory focussed on early childhood (Pellegrini et al., 2007b; Roseth et al., 2007, 2011; Massey et al., 2014; Massey-Abernathy and Byrd-Craven, 2016).

Much research has considered aggressive or coercive behaviour as being socially detrimental, noting its association with socially pathological outcomes for the aggressor (e.g., Crick, 1996; Crick et al., 1997). More recent research suggests that combinations of prosocial and aggressive behaviour can potentially be socially beneficial to the individual and enhance their material or social resource control within the peer-group (Hawley, 1999, 2002, 2003b, 2014; Sutton et al., 1999; Pellegrini et al., 2007b; Pellegrini, 2008; Hawley and Geldhof, 2012; Wettstein et al., 2013). Hawley (2003a) argues that selective and skilled use of coercive or prosocial behaviour within resource contest situations (which she termed 'bistrategic control') was associated with greater success within resource contests and led to superior dominance, whilst other research has evidenced that young children who are well liked can use higher levels of social aggression for resource control purposes, compared to disliked children (Wettstein et al., 2013). However, little research has examined what aspects of the contest situation may be related to how children behave. Insights from Resource Holding Potential/Power (RHP; Parker, 1974) may be relevant here.

Since Darwin the concept of 'resource holding potential/power' (RHP) has been used to explain resourceoriented confrontation (or active avoidance of confrontation) of animals in the their various habitats (Parker, 1974). Parker essentially defines RHP as an organism's ability to maintain or gain control of a resource. According to Parker, across the duration of a conflict, an individual will act to expend their opponent's 'fitness budget', with fitness fundamentally referring to an organism's capability to survive and ultimately produce healthy offspring. An individual's fitness budget, therefore, is determined by (1) the possible gain of fitness if the resource is acquired if the individual is challenging for the resource; or (2) the possible loss of fitness if the individual is being challenged for the resource. The rate of the budget's depletion is dependent on the individual's RHP. The individual must therefore weigh the potential fitness gains/losses associated with attaining/maintaining resource control against the absolute probability of winning the resource contest. Much of the RHPoriented research has focussed extensively on a wide range of non-human animals ranging from sea anemones (Rudin and Briffa, 2012) to white-faced capuchin monkeys (Vogel et al., 2007) and bonobo chimpanzees (Stevens et al., 2005). However, using RHP as a framework, Archer and Benson (2008) investigated the responses of young adult human males to various hypothetical confrontational scenarios, including one in which they were challenged in front of their girlfriend by another man who varied in physical size, number of friends/allies and reputation for toughness, depending on the scenario that was presented. Results showed that the participants responded with greater aggression the lesser the perceived threat (i.e., smaller physical size, fewer allies, and lowered reputation) from the opponent (Archer and Benson, 2008), suggesting that adults may make use of RHP judgements when considering their behaviour in resource-oriented confrontations. Whether similar patterns of behaviour apply to children have not been investigated yet.

Resource holding potential (Parker, 1974) is a concept that innately fits within the theoretical parameters of resource control theory (Hawley, 1999). The nature of an individual's response to a resource opponent's RHP may be particularly relevant for children during their first year of formal schooling where social resources (e.g., the teacher's time or attention of peers) and material resources (e.g., toys/books etc.) are shared among a large group of individuals; other children may want the same resource as them at the same time, which may lead to resource contest situations. The Archer and Benson (2008) study provides a basis for a similar being conducted in young children. In the case of this present study, their approach - varying the opponent's characteristics - was adopted to investigate how varying an opponent's RHP may affect strategy selection, specifically in terms of explicit material resource contest scenarios. Variation in a child's response to scenarios featuring differing opponent characteristics would suggest that they are at least somewhat aware that behavioural approaches should be context dependent. However, as to whether their responses conform to the expected pattern of behaviour described by Parker (1974) or the responses recorded by Archer and Benson (2008) that adhere to Parker's theory deserves investigation.

Archer and Benson (2008) focussed on adult RHP, however, one study has investigated physical size based RHP in young children. Pellegrini et al. (2007b) found that physical size of resource opponents was not in itself treated as a salient indicator of opponent RHP, rather a proxy of age-related resource control-associated This indicates that a young child's behavioural response - that is, strategy selection - in a resource contest situation may well be based on a multifactorial assessment of opponent RHP, as suggested by Archer and Benson's (2008) adult study, rather than simply physical size. It is this potential multifactorial basis of RHP, and how the interplay of those factors associated with strategy selection in young children is of key interest to this present study. 
Importantly, Archer and Benson (2008) focused on coercive behaviour/responses, yet when brought under the umbrella of resource control theory, prosocial responses are also potentially compatible with RHP theory, as Pellegrini et al. (2007b) implies. Strictly under Parker's theory (1974), which focuses on direct resource conflict, it is reasonable to assume that if a multifactorial assessment of opponent RHP suggests too high a risk for a conflict, an individual will withdraw from the resource conflict and the contest is over. However, the overarching resource contest, according to resource control theory (Hawley, 1999), may not be. In this situation, if physical aggression is judged by the individual as too risky (verbal or relational aggression may be deemed too provocative also, given the opponent perceived ability to physically overpower), then prosocial strategies could be selected instead. Now it may be that the individual would still 'win' the resource contest. In the case of young children this could simply be by 'asking nicely' and hoping for some benevolence from the opponent. Alternatively, they may trade or swap resources, which would result in a mutual 'win' i.e., a mutual increase in fitness according to Parker's terminology.

Studies have yet to investigate whether gender has any effect on strategy selection, specifically in the context of resource contest scenarios where opponent RHP has been explicitly identified, as per Archer and Benson (2008). Differences in aggressive and prosocial behaviour between genders is well researched, yet there remains to be seen whether there are differences in prosocial and aggressive behaviour between boys and girls in early childhood. Some research has found young boys to be more physically aggressive and young girls more prosocially behaved (Baillargeon et al., 2007; Poland et al., 2015; Maguire et al., 2016), with girls showing higher levels of relational aggression (Crick et al., 1997, 1999; Poland et al., 2015). Conversely, other research has not found gender differences either in relational aggression (Swit and McMaugh, 2012) or in prosocial behaviour (Swit and McMaugh, 2012; Bouchard et al., 2015). Interestingly, research has found that the gender differences in physical aggression may be more pronounced, with boys evidencing higher reactive physical aggression than girls, but not proactive aggression (Poland et al., 2015). This may have notable consequences on the outcomes of this present study, as a tendency use one type of aggression but not another may result in differential gendered outcomes in specific resource contest outcomes.

This study aimed to investigate the effects of young children's gender on responses to resource contest opponents with varying RHP, indicated by specific characteristics - toughness, presence of friends/allies, and physical size - of the opponent within the scenario. Whilst there is limited research regarding opponent RHP and its effects on behavioural response, what has been done has focussed on adult males (Archer and Benson, 2008) and little is known about the role of RHP during early childhood. This adult data could guide a hypothesis that young children would provide a similar pattern of responses. However, given the significant difference in development, an open question regarding their response patterns in relation to a resource contest opponent's characteristics, rather than a hypothesis, is presented here.
This study also aimed to investigate the association of prosocial and coercive resource control strategy selection with the resource contest opponent RHP. Whilst prior data is scarce, it is plausible to tentatively hypothesis that children tending toward prosocial or coercive strategy selection may respond prosocially or coercively, respectively, more frequently in a resource contest scenario relative to their peers, despite variation in opponent RHP.

\section{MATERIALS AND METHODS}

\section{Participants}

Ninety-two children aged between 4 and 5 years old $(M=4.64$, $S D=0.29$ ) were recruited from 4 reception year classes from 3 state primary schools in the south east of England (males, $n=47$; females, $n=45$ ). No children taking part had any official mental health diagnoses (e.g., ADHD, ASD, conduct disorders). Six children spoke English as a second language and one child was partially sighted but capable of engaging with the activities.

\section{Measures \\ RHP Vignettes}

An adapted version of the Archer and Benson (2008) method was used to assess RHP response. The RHP scenarios were presented as simple stick figure vignettes and shown to the participants using a laptop connected to a separate participant viewing screen. There were 12 different scenarios, allowing for all possible combinations of opponent characteristics (i.e., physical size, 'toughness' and presence of friends/allies).

Participants were shown each of the 12 resource contest scenarios/vignettes. For each slide the researcher provided them with a brief verbal description/tutorial to ensure they understood the task. For example, for the scenario shown in Figure 1: panel A - 'Imagine this is you'; panel B - 'so, who is this? [to check they understood the figure represented them]. That's right!'; panel C 'Now imagine that this boy/girl has the only scooter in school, they're smaller than you, they're not very tough...'; panel D '... and they have friends with them. Imagine that you really want to have this scooter. What you do to get the scooter off them?'

Responses were noted and then categorised following review as either one of five coercive subcategories (ordering/demanding access to the resource, verbal threats or abuse, physical threats, physical attack/grabbing resource, telling teacher) one of four prosocial subcategories (offer to share or help, offer of friendship, asking permission or offering to trade for another resource) or a 'no strategy' response (e.g., saying 'I don't know,' 'I wouldn't do anything,' or a response irrelevant to any strategy or behaviour in the context of the scenario). The initial intent of this measure was to further subcategorise the responses to distinguish between the different coercive and prosocial responses given above, however, physical aggression responses constituted nearly 100\% of the coercive responses, with other coercive responses not sufficient in number to allow statistically meaningful analysis. Therefore, for practicality and clarity of analysis, responses were split into simply either 'prosocial,' 'coercive' or 'no strategy' response categories. 


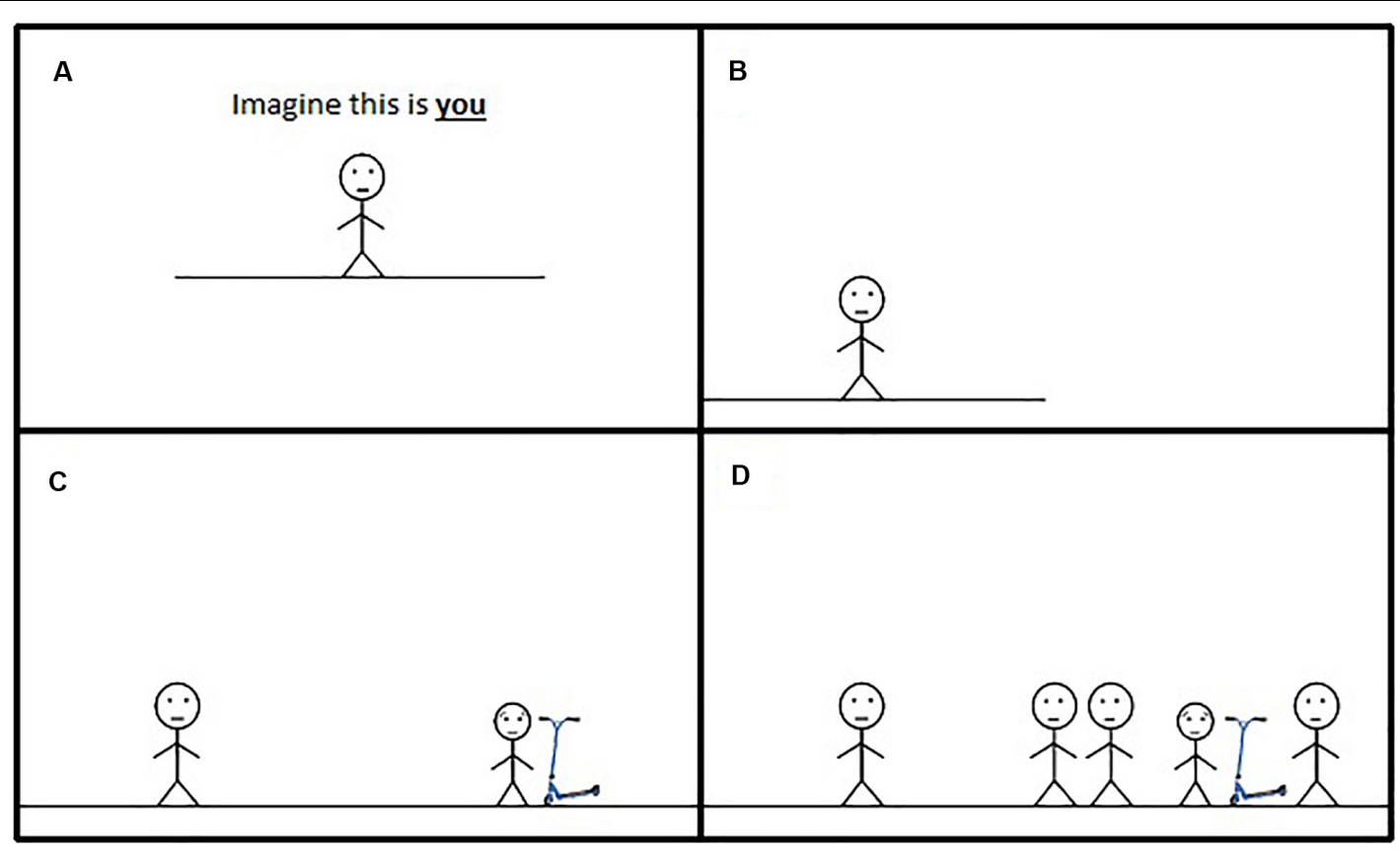

FIGURE 1 | One of the twelve scenarios used in the RHP vignette measure (panel letters added for display purposes in this report only). Slides were presented to each child in the alphabetical order shown. This specific scenario showed a physically smaller [than participant's stick figure representation], not very tough opponent, who was accompanied by friends/allies.

In the event that a child responded with both a prosocial and a coercive response, this would have been deemed a 'bistrategic' response (Hawley, 1999, 2014); however, none of the participants responded in this fashion, therefore categorisation remained as detailed above. The mean number of prosocial, coercive and no strategy responses were then calculated for all scenarios containing a fixed opponent characteristic, with all other characteristics free to vary, e.g., all scenarios featuring a 'very tough' opponent, all scenarios featuring a 'not very tough' opponent, all scenarios featuring a 'bigger than you' opponent etc. had their individual mean scores compiled for prosocial, coercive and no strategy responses.

\section{Verbal Ability}

Children's verbal ability was assessed for control purposes, in order to examine whether potential differences in other variables were the result of differences in receptive vocabulary. This variable was measured with the British Picture Vocabulary Scale III (BPVS III; Dunn et al., 2009) and administered in accordance with the instructions. The standardised scores were used for purposes of analysis.

\section{Procedure}

The investigation was approved by the relevant Institution Research Ethics Committee. Data collection was carried out in the first term of each child's first year at school. Data collection with each class lasted up to two school weeks. Each child was tested individually in a quiet room and their data were collected over two sessions, to reduce fatigue and limit absence from the classroom for extended periods of time. Each session lasted approximately $30 \mathrm{~min}$. The researcher was introduced to the children prior to beginning the data collection and talked to each child participant in a friendly and engaged way for a short period of time to increase their comfort in taking part in the research. The child was told at the beginning of every session that they could stop at any time and verbal assent was given by each child at the start of each session, in addition to parental consent.

\section{Data Analysis}

Initial Pearson's correlations were conducted to examine bivariate associations between age, verbal ability and the RHP scenario responses and to inform use of controls in further analyses (Tables 1, 2).

Independent samples $t$-tests were conducted to establish whether gender had a significant effect on overall frequency of response type (prosocial, coercive or no strategy) across the 12 RHP vignettes. To investigate the effects of young

TABLE 1 | Pearson's bivariate correlations between study variables.

\begin{tabular}{lcccccc}
\hline & $\mathbf{1}$ & $\mathbf{2}$ & $\mathbf{3}$ & $\mathbf{4}$ & $\mathbf{5}$ & $\mathbf{6}$ \\
\hline 1. Age & - & -0.041 & -0.005 & 0.046 & -0.118 & 0.130 \\
2. Gender & & - & $0.317^{\star *}$ & $0.429^{\star *}$ & $-0.410^{* *}$ & -0.037 \\
3. Verbal ability & & & - & $0.322^{\star *}$ & -0.209 & -0.176 \\
4. RHP prosocial response & & & & - & $-0.841^{* *}$ & $-0.280^{\star *}$ \\
5. RHP coercive response & & & & - & $-0.284^{\star *}$ \\
6. RHP 'no strategy' response & & & & & - \\
\hline
\end{tabular}

${ }^{* *}=p<0.01$. 
TABLE 2 | Correlations between variables for boys (above diagonal) and girls (below diagonal) with verbal ability partialled out.

\begin{tabular}{lcccc}
\hline & $\mathbf{1}$ & $\mathbf{2}$ & $\mathbf{3}$ & $\mathbf{4}$ \\
\hline 1. Age & - & 0.205 & -0.241 & 0.114 \\
2. RHP prosocial response & -0.000 & - & $-0.814^{\star \star \star}$ & -0.068 \\
3. RHP coercive response & -0.090 & $-0.826^{\star \star \star}$ & - & $-0.524^{\star \star \star}$ \\
4. RHP no strategy response & 0.146 & -0.422 & -0.163 & - \\
\hline
\end{tabular}

${ }^{* *}=p<0.001$.

children's gender on responses to resource contest opponents with varying RHP, repeated measures analysis of covariance (ANCOVAs) for each gender sub-sample were conducted. Each participant was exposed to vignettes where they would be asked to respond to opponents whose toughness, physical size and presence of friends would qualitatively vary in each vignette. The continuous variables were the mean prosocial/coercive/no strategy response frequencies for the vignettes for each opponent characteristic type (toughness, presence of friends, and physical size) with verbal ability and age for both genders as covariates, with Bonferroni correction applied for post hoc testing were conducted.

\section{RESULTS}

The correlations between the prosocial and coercive vignette response types for each opponent characteristic were highly correlated (Tables 1, 2). Due to the significant correlations between gender and verbal ability, and gender and coercive response frequency, further separate correlations for both boys and girls were conducted, with verbal ability partialled out. The significant correlations involving the RHP vignette responses are described below as they are of key interest.

\section{RHP Responses}

For boys, none of the RHP responses were significantly correlated with age. Prosocial and coercive response frequencies were strongly negatively correlated, with no strategy responses being strongly negatively associated with coercive response frequency only (Table 2). For girls, prosocial and coercive response frequencies were strongly negatively correlated, but no strategy response frequencies showed no significant correlation to any variable (Table 2).

\section{Overall Response Type and Gender}

Independent samples $t$-tests were first conducted to establish whether gender had a significant effect on overall frequency of response type (prosocial, coercive or 'no strategy') across the 12 RHP comprehension scenarios, regardless of opponent characteristics.

Girls $(M=7.88, S D=4.98)$ answered comprehension scenarios significantly more frequently with a prosocial response than boys $(M=3.36, S D=4.66), t(83)=-4.33$, $p<0.001$. Conversely, males $(M=7.38, S D=5.13)$ answered comprehension scenarios significantly more frequently with a coercive response than females $(M=3.05, S D=4.61)$, $t(83)=4.08, p<0.001$. No difference was found in 'no strategy' response frequency between males $(M=1.26, S D=3.13)$ and females $(M=1.26, S D=2.86), t(84)=0.34, p=0.74$.

These tests revealed the same pattern of significant differences between the mean frequencies of prosocial and coercive, but not 'no strategy' responses; males answered more frequently with a coercive response than females, whilst females answered more frequently with a prosocial response than males (Figure 2).

\section{RHP Vignette Response and Opponent RHP Characteristics}

The responses (i.e., prosocial, coercive or 'no strategy') to the RHP vignette scenarios were investigated via a series of repeated measures ANCOVAs for each gender, with age and verbal ability as a covariate, with Bonferroni correction applied for post hoc testing. Post hoc results are displayed in Table 3 and described in detail below. There was no effect of verbal ability for either gender in the following analyses reported.

\section{Toughness of Opponents Prosocial Response Frequency}

In boys, the toughness of the opponent had a significant effect on the prosocial response frequency, $F(1,40)=8.09, p=0.007$, $\omega^{2}=0.14$, with post hoc testing showing prosocial responses were more frequent for 'not very tough' opponents $(M=1.98$, $S D=2.54)$ than for 'very tough' opponents $(M=1.38$, $S D=2.29), p=0.005$. A similar pattern was found for females' prosocial responses, $F(1,41)=10.196, p=0.003, \omega^{2}=0.18$, with the 'not very tough' condition $(M=4.33, S D=2.51)$ associated with higher prosocial response frequency than the 'very tough' condition $(M=3.56, S D=2.71) . p=0.003$. The betweensubjects effects of age was significant for boys, $F(1,40)=5.39$, $p=0.025, \omega^{2}=0.09$, with prosocial responses toward both 'not very tough' opponents, $p=0.021$, and 'very tough' opponents, $p=0.048$, increasing with age. Age effects were not found for girls, $F(1,41)=0.53, p=0.472, \omega^{2}=-0.01$. Examination of interaction effects between age and toughness of opponents revealed no significant effect for males, $F(1,40)=0.935, p=0.34$, $\omega^{2}=-0.002$, or females, $F(1,41)=1.71, p=0.199, \omega^{2}=0.08$.

\section{Coercive Response Frequency}

Initial examination found a significant effect of toughness condition on male coercive response frequency, $F(1,40)=4.73$, $p=0.036, \omega^{2}=0.08$. Post hoc testing found males to respond coercively significantly more frequently toward 'very tough' opponents $(M=3.93, S D=2.64)$ than 'not very tough' opponents $(M=3.45, S D=2.67), p=0.027$. Again, similar patterns emerged for females, $F(1,41)=5.21, p=0.028, \omega^{2}=0.09$, with the 'very tough' condition $(M=1.74, S D=2.54)$ receiving more coercive responses than the 'not very tough' condition $(M=1.30$, $S D=2.23), p=0.028$. The between-subjects effects of age was significant for boys, $F(1,40)=6.26, p=0.017, \omega^{2}=0.11$, coercive responses toward both 'not very tough' opponents, $p=0.009$ and 'very tough' opponents, $p=0.043$, reducing with increased age. Age effects were not found for girls, $F(1,41)=0.15$, $p=0.902, \omega^{2}=-0.02$. No interaction effect was found between 


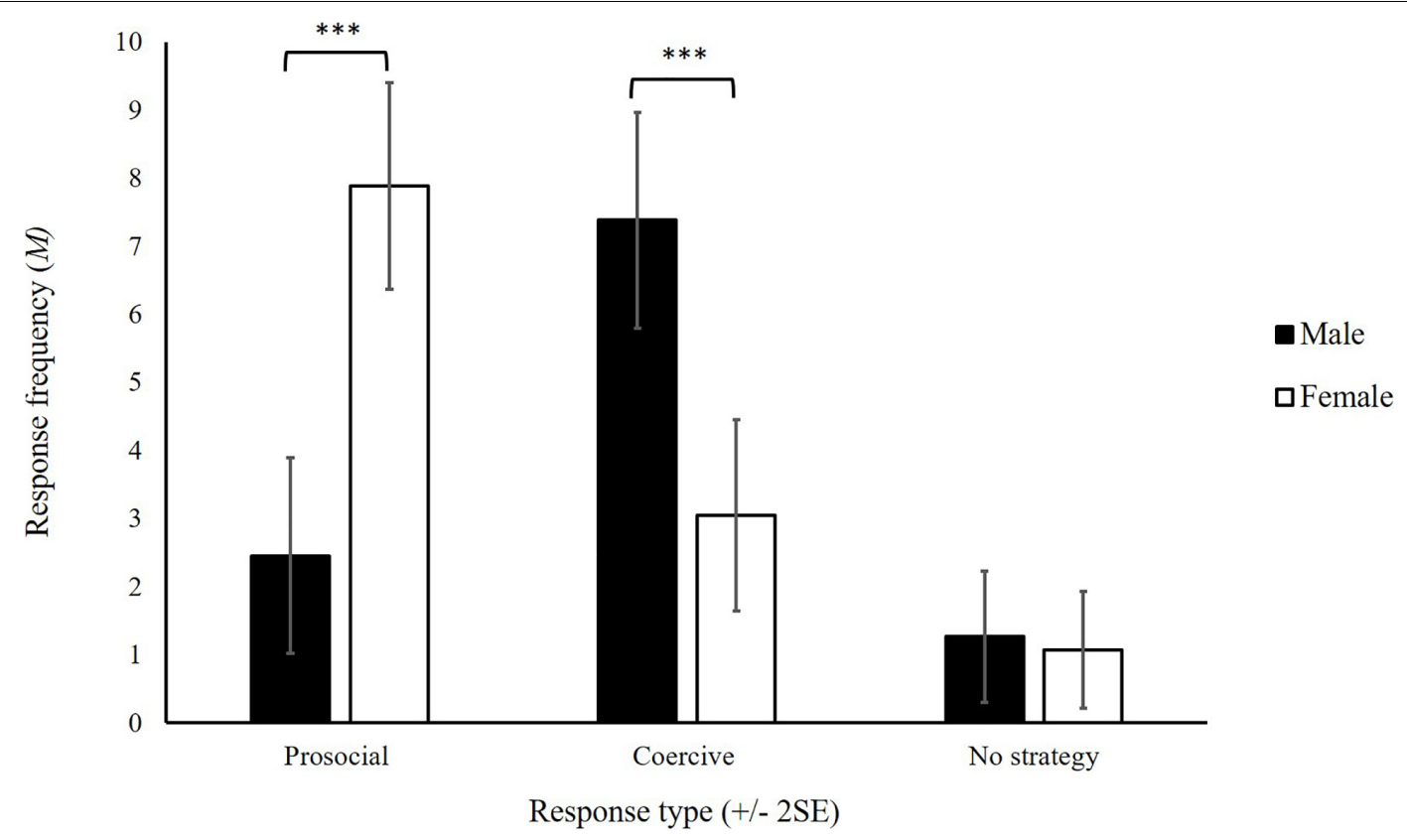

FIGURE 2 | Overall gender differences in response frequency in the RHP vignettes measure. Significance ${ }^{\star \star \star}(p>0.001)$ refers to comparison of response type between genders (shown by the three bar clusters).

TABLE 3 | Repeated-measures ANCOVA post hoc analyses for RHP vignette responses and opponent characteristics.

\begin{tabular}{|c|c|c|c|c|c|c|}
\hline & \multicolumn{3}{|c|}{ Boys } & \multicolumn{3}{|c|}{ Girls } \\
\hline & Prosocial & Coercive & No strategy & Prosocial & Coercive & No strategy \\
\hline \multirow[t]{2}{*}{ Not tough ${ }^{(a)}$} & $1.98^{b}$ & $3.45^{b}$ & 0.57 & $4.33^{b}$ & $1.30^{b}$ & $0.37^{b}$ \\
\hline & $(2.54)$ & (2.67) & (1.48) & (2.51) & (2.23) & $(1.40)$ \\
\hline Very tough ${ }^{(b)}$ & $1.38^{a}$ & $3.93^{a}$ & 0.69 & $3.56^{a}$ & $1.74^{a}$ & $0.70^{a}$ \\
\hline \multirow[t]{2}{*}{ Friends ${ }^{(c)}$} & 1.74 & 3.57 & 0.69 & 3.95 & 1.51 & 0.53 \\
\hline & (2.38) & $(2.51)$ & (1.60) & (2.52) & (2.32) & (1.53) \\
\hline \multirow[t]{2}{*}{ No friends $(\boldsymbol{d})$} & 1.62 & 3.81 & 0.57 & 3.93 & 1.53 & 0.53 \\
\hline & (2.35) & (2.69) & $(1.58)$ & $(2.54)$ & (2.36) & $(1.40)$ \\
\hline \multicolumn{7}{|l|}{ Physical size } \\
\hline Same size $e^{(f)}$ & (1.63) & $(1.80)$ & $(1.00)$ & (1.63) & $(1.47)$ & $(1.00)$ \\
\hline \multirow[t]{2}{*}{ Bigger $(\boldsymbol{g})$} & 1.07 & 2.45 & 0.48 & $2.56^{f}$ & $1.07^{f}$ & 0.37 \\
\hline & (1.55) & $(1.76)$ & $(1.13)$ & $(1.71)$ & $(1.61)$ & $(1.00)$ \\
\hline
\end{tabular}

Means are shown with standard deviations below in parentheses. Significant differences are in bold and superscripted. The superscripts indicate significant differences using Bonferroni correction ( $p<0.05$; unless otherwise stated in the main text). E.g., the top two rows, first column (prosocial), indicate the mean differences in prosocial response frequency between scenarios containing a "not very tough" opponent and a "very tough" opponent.

age and toughness condition for males, $F(1,40)=1.71, p=0.199$ $\omega^{2}=0.80$, or females, $F(1,41)=0.919, p=0.343, \omega^{2}=-0.002$.

\section{'No Strategy' Response Frequency}

There was no significant effect of toughness condition on male 'no strategy' response frequency, $F(1,40)=1.52, p=0.22$, $\omega^{2}=0.01$. However, initial examination found a significant effect of toughness condition on 'no strategy' response in females, $F(1,41)=4.44, p=0.041, \omega^{2}=0.07$, with the 'very tough' condition $(M=0.68, S D=1.67)$ receiving more 'no strategy' responses than the 'not very tough' condition $(M=0.37$, $S D=1.40), p=0.043$. The between-subjects effects of age was 
not significant for boys, $F(1,40)=0.324, p=0.572, \omega^{2}=-0.02$, or for girls, $F(1,41)=1.13, p=0.295, \omega^{2}=0.003$. No interaction effect was found between age and toughness condition for males, $F(1,40)=0.12, p=0.735, \omega^{2}=-0.02$, or females, $F(1,41)=0.691, p=0.411, \omega^{2}=-0.01$.

\section{Presence of Allies/Friends \\ Prosocial Response Frequency}

Initial examination found no significant effect of the presence of friends condition on prosocial response frequency for either males, $F(1,40)=0.85, p=0.361, \omega^{2}=-0.004$, or females, $F(1,41)=0.03, p=0.871, \omega^{2}=-0.02$. The between-subjects effect of age was significant for boys, $F(1,40)=5.39, p=0.025$, $\omega^{2}=0.09$, with prosocial responses toward opponents both opponents with friends, $p=0.021$, and without friends, $p=0.035$, increasing with age. Age effects were not found for girls, $F(1,41)=0.53, p=0.472, \omega^{2}=-0.01$. No interaction effect was found between age and presence of friends condition for males, $F(1,40)=0.42, p=0.519, \omega^{2}=-0.01$, or females, $F(1,41)=0.13$, $p=0.723, \omega^{2}=-0.02$.

\section{Coercive Response Frequency}

Initial examination found no significant effect of presence of friends condition on coercive response frequency for either males, $F(1,40)=2.88, p=0.097, \omega^{2}=0.04$, or females, $F(1,41)=0.03, p=0.856, \omega^{2}=-0.02$. The between-subjects effects of age was significant for boys, $F(1,40)=6.26, p=0.017$, $\omega^{2}=0.11$, with coercive responses toward opponents both with friends, $p=0.007$ and without friends, $p=0.038$, decreasing with increasing age. Age effects were not found for girls, $F(1,41)=0.15, p=0.902, \omega^{2}=-0.02$. No interaction effect was found between age and presence of friends condition for males, $F(1,40)=1.43, p=0.239, \omega^{2}=0.01$, or females, $F(1,41)=0.01$, $p=0.940, \omega^{2}=-0.02$.

\section{‘No Strategy' Response Frequency}

Initial examination found no significant effect of presence of friends condition on 'no strategy' response frequency for either males, $F(1,40)=1.70, p=0.200, \omega^{2}=0.02$, or females, $F(1,41)<0.001, p=0.989, \omega^{2}=-0.02$. The between-subjects effects of age was not significant for boys, $F(1,40)=0.324$, $p=0.572, \omega^{2}=-0.02$, or for girls, $F(1,41)=1.13, p=0.295$, $\omega^{2}=0.003$. No interaction effect was found between age and presence of friends condition for males, $F(1,40)=0.84, p=0.365$, $\omega^{2}=-0.004$, or females, $F(1,41)=0.51, p=0.480, \omega^{2}=-0.01$.

\section{Physical Size of Opponents \\ Prosocial Response Frequency}

Initial examination found no significant effect of the opponent size condition on prosocial response frequency for males, $F(2,80)=0.66, p=0.520, \omega^{2}=0.008$, and no significant effect in females, $F(2,82)=2.95, p=0.058, \omega^{2}=0.04$. The betweensubjects effects of age was significant for boys, $F(1,40)=5.39$, $p=0.025, \omega^{2}=0.09$, prosocial responses toward smaller opponents, $p=0.038$, same-sized opponents, $p=0.019$, and bigger opponents, $p=0.033$ increasing with age. Age effects were not found for girls, $F(1,41)=0.53, p=0.472, \omega^{2}=-0.01$.
No interaction effect was found between age and size condition for males, $F(2,80)=0.565, p=0.571, \omega^{2}=-0.01$, or females, $F(2,82)=1.84, p=0.165, \omega^{2}=0.02$.

\section{Coercive Response Frequency}

Initial examination found no significant effects of opponent size condition on male coercive response frequency, $F(1.75,70.10)=1.76, p=0.183, \omega^{2}=0.02$, but found significant effects in females, $F(2,82)=5.47, p=0.006, \omega^{2}=0.09$. Examination of the within subjects contrasts found a significant quadratic effect, $F(1,41)=8.95, p=0.005, \omega^{2}=0.16$ and post hoc tests showed that the 'same size' condition $(M=0.88, S D=1.47)$ received less female coercive responses than both the 'smaller' condition $(M=1.09, S D=1.60) p=0.033$, and the 'bigger' condition $(M=1.07, S D=1.61), p=0.020$. The between-subjects effects of age was significant for boys, $F(1,40)=6.26, p=0.017$, $\omega^{2}=0.11$, with coercive responses toward smaller opponents, $p=0.010$, to same-sized opponents, $p=0.025$, and bigger opponents, $p=0.024$, decreasing with increasing age. Age effects were not found for girls, $F(1,41)=0.15, p=0.902, \omega^{2}=-0.02$. No interaction effect was found between age and size condition for males, $F(1.75,70.10)=0.148, p=0.836, \omega^{2}=-0.02$, or females, $F(2,82)=2.70, p=0.073, \omega^{2}=0.04$.

\section{'No Strategy' Response Frequency}

Initial examination found no significant effect of opponent size condition on 'no strategy' response frequency for males, $F(2,80)=1.74, p=0.182, \omega^{2}=0.02$, or females, $F(2,82)=0.58$, $p=0.561, \omega^{2}=-0.01$. The between-subjects effects of age was not significant for boys, $F(1,40)=0.324, p=0.572, \omega^{2}=-0.02$, or for girls, $F(1,41)=1.13, p=0.295, \omega^{2}=0.003$. No interaction effect was found between age and size condition for males, $F(2,80)=1.10, p=0.339, \omega^{2}=0.002$, or females, $F(2,82)=0.61$, $p=0.541, \omega^{2}=-0.01$.

\section{DISCUSSION}

This was the first study to attempt to investigate young children's responses to opponent RHP in a resource contest situation. The aims of this study were to investigate the effect of varying opponent RHP on young boys' and girls' strategy choices in hypothetical resource contests, and to examine the association between these responses and real-world teacher ratings of prosocial and coercive behaviour, strategy selection and resource control, and social dominance. Across the 12 scenarios, it was found that girls responded more frequently with prosocial responses and that boys responded more frequently with coercive responses in relative to each other, whilst both boys and girls responded with aggression most frequently toward opponents identified as 'very tough.'

The present study found that, across all 12 scenarios, boys responded coercively to a hypothetical resource opponent more often than girls, who in turn responded prosocially more often than boys. Boys have previously been shown to be more reactively physically aggressive (Poland et al., 2015), however, here, in the hypothetical scenario, they were shown to be far more 
proactively aggressive than girls (to get the resource as the challenger demanded proactive behaviour). This finding, when combined with prior evidence (Poland et al., 2015) suggests that boys of this age may: (1) be aware of social taboos regarding starting a fight but feel they can justify aggressive retaliation; and (2) that they appreciate this vignettes in this present study presented no threat of real-world social taboo from teachers and/or peers that would normally moderate/inhibit proactive aggression. Additionally, the opponent in the vignette does not react in any way, therefore the absence of the threat of social, verbal or physical retaliation from the opponent - which could be an important factor in reality - does not factor into the child's strategy selection. Moreover, the opponent does not react emotionally, therefore a young child (in particular boys in this case) may find it much harder to empathise with the vignette opponent compared to an emotive realworld opponent - another factor that may be instrumental in that data presented here, particularly when considering boys have been shown to behave less empathically than girls (Bensalah et al., 2015).

Yet evidence suggests that young children do have this faculty, at least as far as the ability to assess dominance. Pun and colleagues (Pun et al., 2016, 2017) describe that 6-month-old pre-verbal infants focus on the numerical differences between groups when determining who are the most dominant (and possibly most effective resource controlling) individual; that is to say, a group that is larger in terms of number of constituent individuals will be deemed the dominant group by an infant of 6-months, regardless of how physically large the individuals are in the smaller group. Other research has found that 8-monthold preverbal infants cannot determine dominance based on physical size, but importantly, 10-13-month-olds can (Thomsen et al., 2011). These prior findings suggest that young children are capable of assessing dominance and could therefore appreciate that larger opponents would mean an increased risk of defeat, in line with RHP theory. They also help to explain the lack of significant findings in the present study, for both boys and girls, in terms of response-type frequency's association with the 'friends/allies' condition, as the extant research (Thomsen et al., 2011) suggests older children prioritise factors other than numerical group size when it comes to assessing dominance, though clearly this would need further examination in the age group presented here.

When analysed in more detail, both boys and girls responded coercively more frequently when faced with a very tough' opponent, with boys being more frequently coercive compared to girls. Moreover, participants responded prosocially more frequently to vignettes in which the opponent was described as 'not very tough, with girls being more frequently prosocial compared to boys. These results corroborate previous evidence showing boys during early childhood behaving more aggressively toward peers (Hudziak et al., 2003; for a review, see Coie and Dodge, 1998).

The increased coercive response frequencies against the tough opponents is an interesting finding. Whilst Archer and Benson (2008) found that the adult male participants were more likely to 'back down' from confrontation with increasing opponent threat, the present study found that young children tended to report that they would counter increased toughness with aggression. The age difference between the samples (adult males compared to 4-5-year-old children) is a likely factor contributing to this difference as it brings stark cognitive/affective differences such as executive function and self-regulation to name some. This preschool developmental epoch sees children struggling with (Tremblay, 2000), and learning to control (Bradley, 2000; Phillips and Shonkoff, 2000), aggressive behavioural and affective impulses, therefore increased aggression in this present study [compared to the adult Archer and Benson (2008) study] is to be expected.

It is possible that highlighting the 'toughness' characteristic of the opponents may trigger different behavioural responses in men in the Archer and Benson (2008) study compared to this present study. Specifically, drawing attention to the greater toughness of the opponent as well as their desire for the scooter, a child may plausibly conclude that the most effective strategy is to act equally tough or tougher. Whereas in the Archer and Benson (2008) study the adults recognised their inferior fighting ability, young children may not. Conversely, with an opponent who is highlighted as not being tough, a child may conclude that they wouldn't need to use a coercive strategy to get what they wanted. Though this may seem a plausible explanation for the results of this study, it is tenuous given the dearth of supporting evidence; evidently this requires further investigation before any solid theoretical explanations can be provided.

Evidently, the pattern of increasing aggression in relation to increasing opponent toughness in the child sample presented here is in contrast to that evidenced in adult males (Archer and Benson, 2008) and that predicted by RHP theory itself (Parker, 1974). The responses by Archer and Benson's participants reflect those expected from individuals responding efficiently to balance risk and gain - e.g., reduce the likelihood of an aggressive response when faced with a tougher opponent - whilst the results of this present study are reversed, thus may reflect an immaturity of a child's threat assessment capabilities (Parker, 1974), with threat assessment being innately dependent on cognitive/affective processes.

The child's own interpretation of the vignette opponent's characteristics may have been important. Multiple studies have shown that young children are capable of appreciating moral codes and values (Miller et al., 1996; Kochanska et al., 2002; Eisenberg et al., 2006; Hawley and Geldhof, 2012), therefore such an interpretation of the opponent's character may have led to the child's decision to 'stand up to' the tough opponent, or 'teach them a lesson.' Likewise, some children vocalised their opinion that the 'not very tough' opponents were 'scared' or 'sad.' Thus, it is possible that the prosocial tendency toward these opponents can be explained by empathy, sympathy and/or basic moral code in these children. However, as noted above, the adult scenarios (Archer and Benson, 2008) saw the participant as the resource holder (their girlfriend), compared to this study placing the child as the challenger for the resource, which may therefore explain the reversal of response type between the studies. 
The responses given by both boys and girls - in terms of scenario opponent physical size - support a difference between genders in the present sample. Girls (but not boys) responded coercively less frequently to opponents who were of equal physical size compared to those who were smaller or bigger than their own avatar. Little prior research can explain why such a specific difference in female response in these scenarios would occur. It is possible that girls more readily relate to a peer of similar size which therefore affects their response, with the present finding that girls scored higher in verbal ability than boys being an indication of other cognitive differences that may explain the response difference, such as theory of mind and empathy-based behaviours as discussed above (Walker, 2005; Bensalah et al., 2015). However, this is a tenuous contention and further empirical study is required. Importantly, this is data from the start of the academic year, therefore, whether such gendered trends continue over the course of the first school year remains to be seen.

What remains to be investigated is the relationship between hypothetical resource contest scenarios as presented here and observed resource contest behaviours in real-world environments, e.g., in the classroom. It is possible that the children in this sample were enacting a fantasy scenario in which they selected a coercive resource control strategy and overpowered the tougher and/or physically larger dominant resource holder. The prior research suggests they have the capability to detect dominance in others, or at least what they perceive to be dominance (Thomsen et al., 2011); that physical size is related to aggressive resource contest victory in early childhood (Hawley and Little, 1999; Pellegrini et al., 2007a,b; Roseth et al., 2007), yet the findings presented here provide no data to elucidate the relationship between child vignette responses to observed real world resource-directed behaviours. It may be that these children who seemingly counter Parker's (1974) theory are effectively using the hypothetical scenarios to express what they would do in reality to a dominant resource holder if they could get away with it socially (no taboos broken, no damaged relationships with peers or teachers) and physically (no chance of physical retaliation from superior opponent). In other words, children may be too aware that this is a 'game' rather than a genuine opportunity to gain a desired resource and therefore select (vocalise) a strategy that they deemed fun and/or cathartic in the game, rather than one that they would chose in a real contest situation in order to win the resource. Evidently this requires investigation in further work involving direct observation.

Future research beyond this study must investigate the multifactorial influences on behavioural response to opponent RHP via detailed observational study, the absence of direct observational data being a limitation of the present study. It may be when the children are the resource contender in real-world contests, rather than the hypothetical ones posed to them in this present study, that their actual behaviour, compared to their vocalised opinions about how they would behave, are different. Perhaps the consideration of their opponent's RHP is not a significant factor at all in real situations in early childhood; rather findings presented here may act to focus the child's attention to the vignette opponent, something that may not occur in real-life, e.g., perhaps wanting that (real) scooter would be too tempting and the child's knowledge that their opponent is too strong would be insufficient to prevent them attacking the opponent anyway. Additionally, perhaps children consider the longer-term friendship that may be at stake with the resource opponent in real life, whereas in the RHP vignettes presented here, their sole target was the material resource and not the social one as well. This is a very important point to consider in future work, especially in light of the work of Pellegrini, Roseth and colleagues (Pellegrini et al., 2011; Roseth et al., 2011) which empirically suggests that children in this age group may well consider such social resource ramifications when involved in material resource struggles, as reconciliation behaviour is often a key strategic approach to both achieve immediate material resource control, and possibly limit negative social ramifications (social resource control) in the longer term. Investigations of the effect of control of the contested resource should also be conducted; the current study forced the participants to assume the challenger role yet being in possession of the resource initially may elicit different responses.

This was the first study to examine young children's responses to opponent RHP in a resource contest situation. Interestingly, the children's strategy choices in the hypothetical resource control vignettes reflect previous real-world findings of prosocial and coercive behaviour generally (e.g., Baillargeon et al., 2007; Poland et al., 2015; Maguire et al., 2016). The gender differences found point to interesting cognitive differences between young boys and girls that may yet play out in the real world when more specifically investigated in future; it seems unlikely that the implicit gendered cognitive differences exhibited in the vignettes are entirely ineffectual in other real-world scenarios. Measures of other cognitive and affective attributes are required in order to elucidate the role of such capacities may have on whether or not young children apply resource control strategies to a contest based solely on response to opponent RHP, or whether, for example, empathy or moral understanding play a significant role in strategy selection that may counter what is stipulated by RHP theory (Parker, 1974).

\section{CONCLUSION}

Whilst the study has not provided observational data, it has provided novel evidence for young children's capacity to acknowledge differences in a resource opponent's characteristics and to adjust their behaviour in light of that acknowledgement. Whether this capacity translates into an efficient real-world RHP assessment (as defined by Parker, 1974) remains to be elucidated in future study, from which practical implications of this line of research for educational professionals can be drawn.

\section{DATA AVAILABILITY STATEMENT}

The raw data supporting the conclusions of this article will be made available by the authors, without undue reservation. 


\section{ETHICS STATEMENT}

The studies involving human participants were reviewed and approved by The University of Greenwich Research Ethics Committee (UREC). Written informed consent to participate in this study was provided by the participants' legal guardian/next of kin.

\section{AUTHOR CONTRIBUTIONS}

AR was the primary author of the manuscript. All authors contributed to the writing and editing of the manuscript.

\section{REFERENCES}

Archer, J., and Benson, D. (2008). Physical aggression as a function of perceived fighting ability and provocation: an experimental investigation. Aggress. Behav. 34, 9-24. doi: 10.1002/ab.20179

Baillargeon, R. H., Keenan, K., Wu, H. X., Zoccolillo, M., Côté, S., Pérusse, D., et al. (2007). Gender differences in physical aggression: a prospective populationbased survey of children before and after 2 years of age. Dev. Psychol. 43, 13-26. doi: 10.1037/0012-1649.43.1.13

Bensalah, L., Caillies, S., and Anduze, M. (2015). Links between cognitive empathy, theory of mind, and affective perspective taking by young children. J. Genet. Psychol. 1325, 17-31. doi: 10.1080/00221325.2015.1106438

Bernstein, I. S. (1981). Dominance: the baby and the bathwater. Behav. Brain Sci. 4, 419-457. doi: 10.1017/S0140525X00009614

Bouchard, C., Coutu, S., Bigras, N., Lemay, L., Cantin, G., Bouchard, M. C., et al. (2015). Perceived, expressed and observed prosociality among four-year-old girls and boys in childcare centres. Early Child Dev. Care 185, 44-65. doi: 10.1080/03004430.2014.903940

Bradley, S. J. (2000). Affect Regulation and the Development of Psychopathology. New York, NY: Guilford Press.

Charlesworth, W. R. (1996). Co-operation and competition: contributions to an evolutionary and developmental model. Int. J. Behav. Dev. 19, 25-38. doi: $10.1177 / 016502549601900103$

Chen, B.-B. (2017). Insecure attachment, resource control, and unrestricted sociosexuality: From a life history perspective. Pers. Individ. Dif. 105, 213-217. doi: 10.1016/j.paid.2016.09.062

Chen, B.-B., and Chang, L. (2012). Adaptive insecure attachment and resource control strategies during middle childhood. Int. J. Behav. Dev. 36, 389-397. doi: $10.1177 / 0165025412445440$

Coie, J. D., and Dodge, K. A. (1998). “Aggression and antisocial behavior," in Handbook of Child Psychology: Vol. 3. Social, Emotional, and Personality Development, eds W. Damon and N. Eisenberg (New York, NY: Wiley), $779-862$.

Crick, N. R. (1996). The role of overt aggression, relational aggression, and prosocial behavior in the prediction of children's future social adjustment. Child Dev. 67, 2317-2327. doi: 10.2307/1131625

Crick, N. R., Casas, J. F., and Ku, H. C. (1999). Relational and physical forms of peer victimization in preschool. Dev. Psychol. 35, 376-385. doi: 10.1037/00121649.35.2.376

Crick, N. R., Casas, J. F., and Mosher, M. (1997). Relational and overt aggression in preschool. Dev. Psychol. 33, 579-588. doi: 10.1037/0012-1649.33. 4.579

Dunn, D. M., Dunn, L. M., and National Foundation for Educational Research in England and Wales. (2009). The British Picture Vocabulary Scale, 3rd Edn. GL Assessment.

Eisenberg, N., Fabes, R. A., and Spinrad, T. L. (2006). "Relation of emotion-related regulation to children's social competence: a longitudinal study," in Handbook of Child Psychology: Vol. 3. Social, Emotional and Personality Development, 6th Edn, eds W. Damon, R. M. Lerner, and N. Eisenberg (New York, NY: Wiley), 646-718.

\section{FUNDING}

This research was funded by the University of Greenwich, United Kingdom.

\section{ACKNOWLEDGMENTS}

The authors would like to thank the University of Greenwich for providing the facilities to carry out the data analysis for this research and to those participating schools and staff during the data collection phase.

Hawley, P. H. (1999). The ontogenesis of social dominance: a strategy-based evolutionary perspective. Dev. Rev. 19, 97-132. doi: 10.1006/drev.1998. 0470

Hawley, P. H. (2002). Social dominance and prosocial and coercive strategies of resource control in preschoolers. Int. J. Behav. Dev. 26, 167-176. doi: 10.1080/ 01650250042000726

Hawley, P. H. (2003a). Prosocial and coercive configurations of resource control in early adolescence: a case for the well-adapted machiavellian. Merrill Palmer Q. 49, 279-309. doi: 10.1353/mpq.2003.0013

Hawley, P. H. (2003b). Strategies of control, aggression, and morality in preschoolers: an evolutionary perspective. J. Exp. Child Psychol. 85, 213-235. doi: 10.1016/S0022-0965(03)00073-0

Hawley, P. H. (2014). Ontogeny and social dominance: a developmental view of human power patterns. Evol. Psychol. 12, 318-342. doi: 10.1177/ 147470491401200204

Hawley, P. H., and Geldhof, J. G. (2012). Preschoolers' social dominance, moral cognition, and moral behavior: an evolutionary perspective. J. Exp. Child Psychol. 112, 18-35. doi: 10.1016/j.jecp.2011.10.004

Hawley, P. H., and Little, T. D. (1999). On winning some and losing some: a social relations approach to social dominance in toddlers. Merrill Palmer Q. J. Dev. Psychol. 45, 185-214.

Hawley, P. H., Shorey, H. S., and Alderman, P. M. (2009). Attachment correlates of resource-control strategies: possible origins of social dominance and interpersonal power differentials. J. Soc. Pers. Relat. 26, 1097-1118. doi: 10.1177/ 0265407509347939

Hudziak, J. J., Van Beijsterveldt, C. E. M., Bartels, M., Rietveld, M. J. H., Rettew, D. C., Derks, E. M., et al. (2003). Individual differences in aggression: genetic analyses by age, gender, and informant in 3-, 7-, and 10-year-old Dutch twins. Behav. Genet. 33, 575-589. doi: 10.1023/A:1025782918793

Kochanska, G., Gross, J. N., Lin, M.-H., and Nichols, K. E. (2002). Guilt in young children: development, determinants, and relations with a broader system of standards. Child Dev. 73, 461-482. doi: 10.1111/1467-8624.00418

Maguire, L. K., Niens, U., McCann, M., and Connolly, P. (2016). Emotional development among early school-age children: gender differences in the role of problem behaviours. Educ. Psychol. 36, 1408-1428. doi: 10.1080/01443410. 2015.1034090

Massey, A. R., Byrd-Craven, J., and Swearingen, C. L. (2014). Preschool power play: resource control strategies associated with health. Child Dev. Res. 2014, 1-7. doi: 10.1155/2014/706547

Massey-Abernathy, A., and Byrd-Craven, J. (2016). Functional leadership: Bistrategic controllers high on effortful control show gains in status and health. Pers. Individ. Dif. 97, 193-197. doi: 10.1016/j.paid.2016.03.039

Miller, P. A., Eisenberg, N., Fabes, R. A., and Shell, R. (1996). Relations of moral reasoning and vicarious emotion to young children's prosocial behavior toward peers and adults. Dev. Psychol. 32, 210-219. doi: 10.1037/0012-1649.32.2.210

Parker, G. (1974). Assessment strategy and the evolution of animal conflicts. J. Theor. Biol. 47, 223-243.

Pellegrini, A. D. (2008). The roles of aggressive and affiliative behaviors in resource control: a behavioral ecological perspective. Dev. Rev. 28, 461-487. doi: 10.1016/ j.dr.2008.03.001 
Pellegrini, A. D., Long, J. D., Roseth, C. J., Bohn, C. M., and Van Ryzin, M. (2007a). A short-term longitudinal study of preschoolers' (Homo sapiens) sex segregation: the role of physical activity, sex, and time. J. Comp. Psychol. 121, 282-289. doi: 10.1037/0735-7036.121.3.282

Pellegrini, A. D., Roseth, C. J., Mliner, S., Bohn, C. M., Van Ryzin, M., Vance, N., et al. (2007b). Social dominance in preschool classrooms. J. Comp. Psychol. 121, 54-64. doi: 10.1037/0735-7036.121.1.54

Pellegrini, A. D., Van Ryzin, M. J., Roseth, C. J., Bohn-Gettler, C., Dupuis, D. N., Hickey, M. C., et al. (2011). Behavioral and social cognitive processes in preschool children's social dominance. Aggress. Behav. 37, 248-257. doi: 10. 1002/ab.20385

Phillips, D. A., and Shonkoff, J. P. (2000). From Neurons to Neighborhoods: The Science of Early Childhood Development. Washington, D.C: National Academies Press.

Poland, S. E., Monks, C. P., and Tsermentseli, S. (2015). Cool and hot executive function as predictors of aggression in early childhood: differentiating between the function and form of aggression. Br. J. Dev. Psychol. 34, 181-197. doi: 10.1111/bjdp. 12122

Pun, A., Birch, S. A. J., and Baron, A. S. (2016). Infants use relative numerical group size to infer social dominance. Proc. Natl. Acad. Sci. U.S.A. 113, 2376-2381. doi: $10.1073 /$ pnas. 1514879113

Pun, A., Birch, S. A. J., and Baron, A. S. (2017). Foundations of reasoning about social dominance. Child Dev. Perspect. 11, 155-160. doi: 10.1111/cdep.12235

Roseth, C. J., Pellegrini, A. D., Bohn, C. M., Van Ryzin, M., and Vance, N. (2007). Preschoolers' aggression, affiliation, and social dominance relationships: an observational, longitudinal study. J. Sch. Psychol. 45, 479-497. doi: 10.1016/j. jsp.2007.02.008

Roseth, C. J., Pellegrini, A. D., Dupuis, D. N., Bohn, C. M., Hickey, M. C., Hilk, C. L., et al. (2011). Preschoolers' bistrategic resource control, reconciliation, and peer regard. Soc. Dev. 20, 185-211. doi: 10.1111/j.1467-9507.2010.00579.x

Rudin, F. S., and Briffa, M. (2012). Is boldness a resource-holding potential trait? Fighting prowess and changes in startle response in the sea anemone, Actinia equina. Proc. R. Soc. B Biol. Sci. 279, 1904-1910. doi: 10.1098/rspb.2011.2418

Stevens, J. M. G., Vervaecke, H., De Vries, H., and Van Elsacker, L. (2005). Peering is not a formal indicator of subordination in bonobos (Pan paniscus). Am. J. Primatol. 65, 255-267. doi: 10.1002/ajp.20113
Sutton, J., Smith, P. K., and Swettenham, J. (1999). Social cognition and bullying: social inadequacy or skilled manipulation? Br. J. Dev. Psychol. 17, 435-450. doi: 10.1348/026151099165384

Swit, C., and McMaugh, A. (2012). Relational aggression and prosocial behaviours in Australian preschool children. Aus. J. Early Child. 37, 30-34. doi: 10.1177/ 183693911203700305

Thomsen, L., Frankenhuis, W. E., Ingold-Smith, M., and Carey, S. (2011). Big and mighty: preverbal infants mentally represent social dominance. Science 331, 477-480. doi: 10.1126/science. 1199198

Tremblay, R. E. (2000). The development of aggressive behaviour during childhood: what have we learned in the past century? Int. J. Behav. Dev. 24, 129-141. doi: 10.1080/016502500383232

Trivers, R. L. (1971). The evolution of reciprocal altruism. Q. Rev. Biol. 46, 35-57. doi: $10.1086 / 406755$

Vogel, E. R., Munch, S. B., and Janson, C. H. (2007). Understanding escalated aggression over food resources in white-faced capuchin monkeys. Anim. Behav. 74, 71-80. doi: 10.1016/j.anbehav.2007.02.003

Walker, S. (2005). Gender differences in the relationship between young children's peer-related social competence and individual differences in theory of mind. J. Genet. Psychol. 166, 297-312. doi: 10.3200/GNTP.166.3. 297-312

Wettstein, A., Brendgen, M., Vitaro, F., Guimond, F. A., Forget-Dubois, N., Cantin, S., et al. (2013). The additive and interactive roles of aggression, prosocial behavior, and social preference in predicting resource control in young children. J. Aggress. 5, 179-196. doi: 10.1108/JACPR-11-2012-0011

Conflict of Interest: The authors declare that the research was conducted in the absence of any commercial or financial relationships that could be construed as a potential conflict of interest.

Copyright (c) 2020 Roberts, Monks and Tsermentseli. This is an open-access article distributed under the terms of the Creative Commons Attribution License (CC BY). The use, distribution or reproduction in other forums is permitted, provided the original author(s) and the copyright owner(s) are credited and that the original publication in this journal is cited, in accordance with accepted academic practice. No use, distribution or reproduction is permitted which does not comply with these terms. 